УДК 581.527 .4

DOI: $10.21779 / 2542-0321-2017-32-3-111-117$

\title{
3.3. Шахбанова
}

\section{Первичная диагностика возрастных состояний Onobrychis majorovii Grossh}

Дагестанский государственный университет; Россия, 367001, г. Махачкала, ул. М. Гаджиева, 43a; shahbanova.zaryat@yandex.ru

В работе предпринята первичная попытка диагностировать возрастные состояния большого жизненного цикла Onobrychis majorovii Grossh на песчаном массиве Сарыкум, расположенном в предгорной геоморфологической части Республики Дагестан. Onobrychis majorovii псаммофильный, поликарпический многолетник, гелиофит, является эндемиком Восточного Кавказа. Впервые обнаружен на территории этого песчаного памятника природы и описан А.А. Майоровым в 1928 году. Растение произрастает в заповедной части массива, на южном склоне, ближе к основанию, оно является исключительно декоративным во время массового цветения в мае. Данными, использованными для написания статьи, являются полевые сборы 2016 года, выполненные в щадящем режиме без выкопки растений с учетом заповедной территории обследования. Для изучения особенностей морфологии особей и вычленения онтогенетического периода и возрастного состояния мы использовали качественные (жилкование, форма и тип листа, особенности роста побегов, вес, цвет семенной кожуры и форма семени) и количественные (количество признаков вегетативной и генеративной сфер) морфометрические признаки. Большой жизненный цикл Onobrychis majorovii представлен 4 онтогенетическими периодами и 9 возрастными состояниями. Дана подробная характеристика каждого возрастного состояния и особенности его выделения в рамках большого жизненного цикла Onobrychis majorovii, основываясь на данных первичных полевых исследований и некоторых данных более ранних исследований К.Ю. Абачева. Сделаны предварительные выводы о демографической структуре изучаемой ценопопуляции.

Ключевые слова: Onobrychis majorovii, жизненный иүикл, возрастные периоды.

\section{Введение}

Фитоценозы предгорной части Республики Дагестан характеризуются богатым и в то же время уникальным флористическим составом. Большинство входящих в них видов растений представляют собой ценный материал для научных исследований, дающих возможность принятия конкретных мер для сохранения природных популяций. В последнее время особое значение придается изучению эндемичных и редких видов [1-3]. Среди них находится типичный представитель песчаного субстрата Onobrychis majorovii, который является объектом наших исследований. Растение обитает на сухих песчаных и галечниковых склонах низменностей и предгорий Дагестана [4-6]. Кроме того, Onobrychis majorovii встречается в аналогичных экотопах Ставропольского края, а также Брагуно-Новолакского и Терско-Сунженского районов Чеченской Республики [7, 8]. Это эндемичное для восточной части Кавказа растение впервые описал А.А. Майоров на массиве Сарыкум $[9,10]$.

Серия 1. Естественные науки. 2017. Том 32. Вып. 3 
Onobrychis majorovii - это стержнекорневой многолетний травянистый ксерофильный вид, высотой генеративных побегов до 40-60 см, с рыхло-ветвистыми стеблями. Цветки образуют соцветие - кисть. Плод - боб, 12-14 мм длиной, более или менее мохнато-волосистый, реже почти голый с шипами по краям. Зрелые плоды соломенножелтого цвета. Семена твердокаменные могут прорастать после 4-5-летнего хранения. Вегетирует растение с мая по июль [11].

Популяционное исследование Onobrychis majorovii на массиве Сарыкум началось сравнительно недавно [12], и в настоящее время проводится всесторонний анализ биологии и экологии этого вида. В рамках данной работы представлены результаты изучения онтогенеза его Сарыкумской ценопопуляции.

\section{Методы исследования}

Исследование проводилось в мае-июне 2016 года. С целью полевого исследования ценопопуляции Onobrychis majorovii было осуществлено несколько выездов на песчаный массив Сарыкум. Случайным методом были заложены 12 учетных площадей раз-

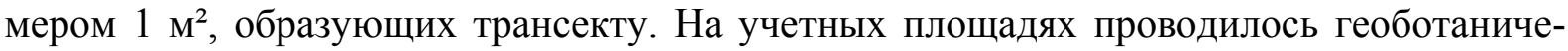
ское описание по стандартной методике, во время которого отмечались доминирующие виды, фиксировалась встречаемость изучаемого растения, проводился подсчет особей, определялось число особей в каждом возрастном состоянии и проводилось фотографирование [13-15].

Полевые сборы ограничили одним генеративным побегом на растение. Собранный материал высушивался в лабораторных условиях, после чего изучалось морфологическое строение особей всех возрастных периодов и состояний. Для выделения возрастных периодов пользовались собственными наблюдениями и материалами статьи Е.А. Брынза [16]. В качестве изучаемых признаков использовались: для латентных объектов - длина, ширина, цвет, особенности поверхности, форма, всхожесть семени; для прегенеративного периода - типы побегов по развитию междоузлий и их размеры, типы и размеры листьев, жилкование, количество листьев, особенности корневой системы и ее размеры; для генеративного периода - количество листьев на побег, длина и ширина листа, количество листочков на сложный лист, количество генеративных побегов на растение, количество соцветий на генеративный побег, высота генеративного побега и соцветия, количество цветков и плодов на соцветие, длина и ширина флага, длина и высота лодочки, длина чашечки; для сенильного периода - соотношение процессов новообразования и отмирания, количественные морфометрические признаки. Далее производилось зарисовка возрастных состояний изучаемого растения.

\section{Результаты исследования}

Анализ качественных морфопараметров побегов Onobrychis majorovii позволил охарактеризовать онтогенетические периоды и выделить возрастные состояния изучаемого растения в рамках Сарыкумской ценопопуляции.

Латентный период. Представлен семенами (двусемянными плодами - бобами). Из двух семян плода одно обычно недоразвитое и более мелких размеров, второе же имеет стандартную форму и размеры. Семена Onobrychis majorovii различаются не только по окраске (песочные и коричневые) и размеру (мелкие и крупные), но и по абсолютному весу, причем эти признаки находятся во взаимной зависимости друг от друга. Так, самый низкий абсолютный вес наблюдается у семян в случае, если в плоде одно 
мелкое семя светлой окраски (7-3 мг), а высокий, когда одно крупное семя коричневой окраски (15,7 мг). Высеянные семена при набухании ослизняются и теряют пигментацию кожуры, приобретая при этом светло-желтую окраску. Нежизнеспособные семена, сильно ослизняясь, на 5-6 день начинают покрываться грибковой плесенью и погибают. Жизнеспособные же семена, начиная со 2-3 дня, прорастают преимущественно одним из четырех типов, указанных К.Ю. Абачевым [17] для некоторых других бобовых растений.

Всхожесть семян Onobrychis majorovii зависит от их фенотипа. Так, энергия прорастания выше у крупных светлых семян из двусемянных плодов, немного ниже у крупных семян из односемянных плодов и совсем низкая - у мелких светлых семян из двусемянных плодов.

Прегенеративный период. Это молодой период, когда растение не способно к генеративному размножению. Он разделяется на несколько возрастных состояний:

1. Проростки (pl). У Onobrychis majorovii прорастание надземное, однако околоплодник односемянных плодов сохраняется как бы продетым сквозь побег долгое время. Семядоли имеют округло-продолговатую форму и вскоре после их позеленения появляется 1-2 простых листа длиной менее 0,8-1,4 см. Жилкование таких листьев перистое, но боковых жилок очень мало. Черешок такого листа длиннее листовой пластинки - 1,5-3 см. После простых листьев в розетке проростка появляется от 1 до 4 тройчатосложных листьев (рис.). Длина их черешка может составлять до 5 см, а длина листочков - от 0,5 до 1,5 см при ширине 3-6 мм. Черешочек верхнего листочка гораздо длиннее, чем черешочки боковых. Таким образом, листья напоминают непарноперистосложные. Высота розетки составляет 3-6 см.

2. У ювенильных растений (j) полностью утрачена связь с семенем. Количество листьев в розетке увеличивается до 5-6. Листья становятся непарноперистосложными, обычно с 5 листовыми пластинками. В редких случаях могут встречаться и парноперистосложные листья с 4 листовыми пластинками. Длина листовой пластинки такого сложного листа колеблется от 0,8 до 2 см, ширина находится в диапазоне от 0,5 до $1 \mathrm{~cm}$. У некоторых особей сохраняются тройчатосложные листья (рис.), но в небольшом количестве. У редких экземпляров сохраняются простые округлые листья. Высота ювенильного растения находится в диапазоне от 6,5 до $10 \mathrm{~cm}$. Корневая система у этих растений так же, как и у проростков, стержневая, главный корень не обнаруживает строгой геотропической реакции, пробка окрашена в ярко-оранжевый цвет. Боковые корни в крайне незначительном количестве и небольших размеров. При изучении ценопопуляции оказалось, что особи ранней стадии развития Onobrychis majorovii расположены вокруг взрослого генеративного растения довольно крупными скоплениями.

3. Имматурные растения (im). У этого возрастного состояния побег становится удлиненным, но не ветвится. Междоузлия увеличиваются до 0,5-1 см длиной, количество листьев небольшое (5-6 шт.). Листья непарноперистосложные, простые и тройчатосложные листья отсутствуют (рис.). Длина листа колеблется от 5 до 12 см. Он представлен 7-11 листочками, длина которых обычно не более 1,5 cм, а ширина - не более 0,8 см. Высота имматурных растений составляет 10-13 см. Корневая система обнаруживает боковое ветвление и более протяженные размеры главного корня.

4. Виргинильные растения (v) характеризуются явно выраженным удлиненным главным побегом. Количество междоузлий 6-7. Все листья непарноперистосложные с 13-15 листочками, их длина приблизительно такая же, как у имматурных растений. По- 
беги не ветвятся, но утратили розеточность (рис.). Высота побегов составляет 15-18 см, с хорошо выраженным опушением главного побега, зачатки которого появляются еще у имматурных растений. Корневая система более глубокая и разветвленная. Пробка, покрывающая корни, темно-коричневого цвета.

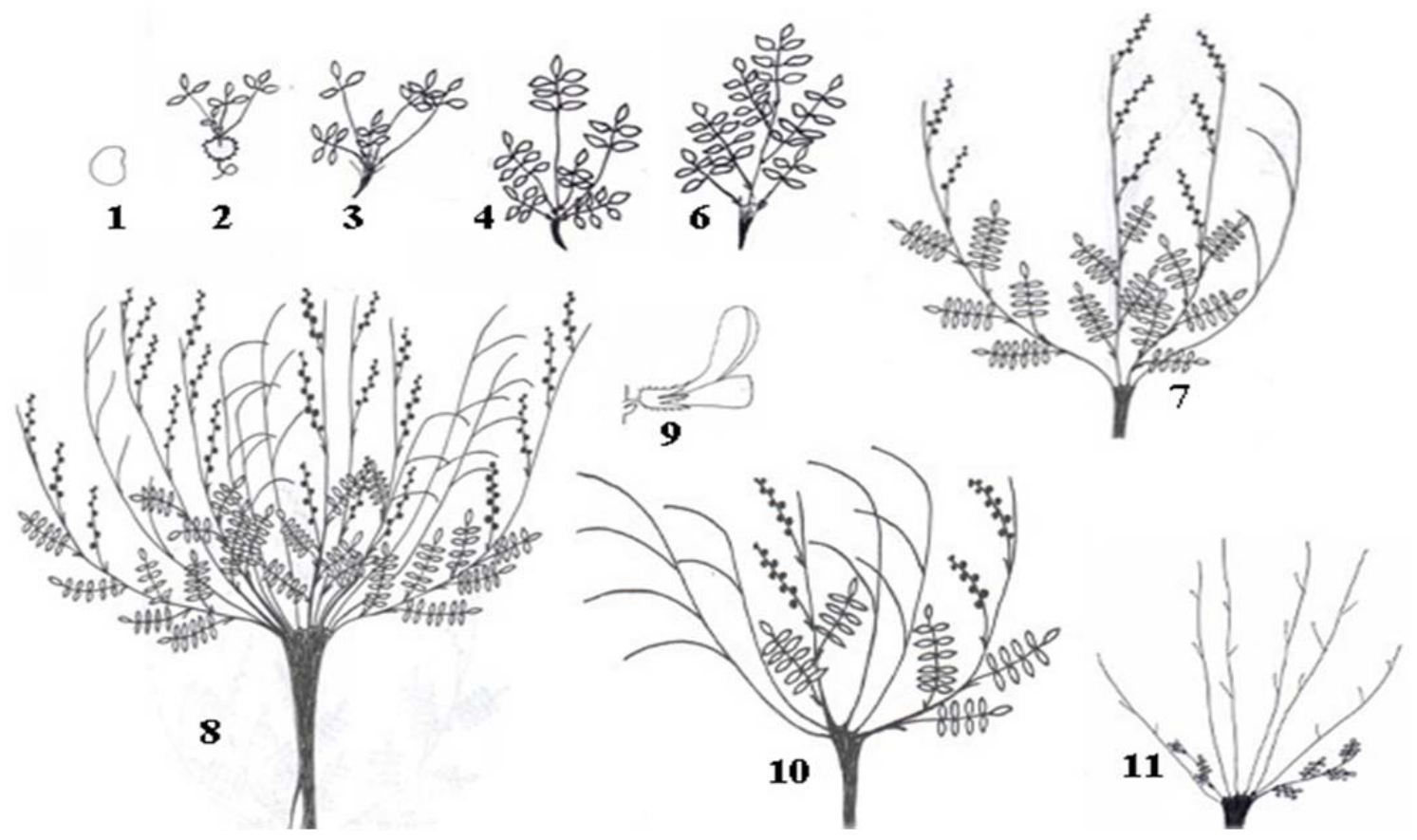

Рис. Возрастные состояния Onobrychis majorovii

$\left(1-s m, 2-p l, 3-j, 4-i m, 5-v, 6-g_{1}, 7-g_{2}, 8-g_{3}, 9-\right.$ цветок, $\left.10-s\right)$

Генеративный период у Onobrychis majorovii характеризуется молодыми растениями, у которых появляется возможность плодоношения. Условно этот период можно разделить на молодые $\left(g_{1}\right)$, средневозрастные $\left(g_{2}\right)$ и старческие $\left(g_{3}\right)$ генеративные растения. По соотношению процессов новообразования и разрушения можно (иногда не очень четко) различать эти периоды.

5. Молодые генеративные особи $\left(g_{l}\right)$ формируют некрупные мало ветвящиеся побеги длиной 20-25 см. Генеративных побегов они образуют от 1 до 4, часто на общем побеге появляются и вегетативные, укороченные побеги. Количество листьев на общем побеге тоже не превышает 10. Размеры листочков сложного листа небольшие: ширина их составляет 0,8 см, длина - 1 см. Количество листочков сложного листа - 11-13. Соцветие - кисть длиной приблизительно 12 см, количество цветков крайне незначительное (в пределах 10).

6. У средневозрастных генеративных растений $\left(g_{2}\right)$ наблюдаются более крупные размеры. Количество генеративных побегов на растение составляет от 5 до 20 и в среднем равно 8,61 $\pm 0,63$. Количество молодых вегетирующих побегов генеративного типа и отмерших побегов предыдущего года приблизительно одинаково при незначительном преобладании первых (рис.). Высота генеративных побегов в среднем составляет $62,36 \pm 1,54$ см при минимальной высоте 45 см и максимальной 77 см. На генеративном 


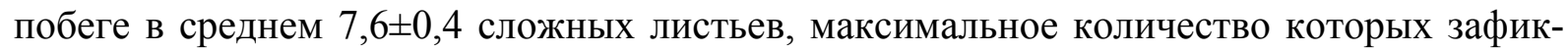
сировано в пределах 12, а минимальное - 4. Листья имеют длину, равную 14,8 $\pm 0,39$ см, ширину $-5,1 \pm 0,14$ см и состоят из 13 листочков. Длина и ширина верхних листочков сложных листьев составляют $1,4 \pm 0,04$ см и $0,8 \pm 0,03$ см соответственно. На генератив-

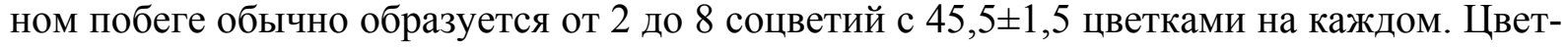
ки имеют следующие параметры морфометрии: длина флага составляет $1,6 \pm 0,05 \mathrm{~cm}$, а ширина $-1,4 \pm 0,02 \mathrm{~cm}$, длина лодочки - 1,5 $\pm 0,3 \mathrm{~cm}$, а ее высота $-0,7 \pm 0,02 \mathrm{~cm}$, чашечка цветка имеет длину $0,7 \pm 0,02$ см. На одном генеративном побеге средневозрастного генеративного растения формируется $43,2 \pm 1,9$ плодов. В связи с тем, что растения находятся на охраняемой заповедной территории, выкапывание не производилось и корневую систему не наблюдали.

7. В группе старческих генеративных растений $\left(g_{3}\right)$ Onobrychis majorovii можно отметить особи с большим количеством сухих побегов прошлого года (до 10). В то же время побегов текущего года обычно бывает в 2 раза меньше. Показатели морфометрии этих особей не намного ниже, чем у генеративного средневозрастного состояния. Однако на генеративном побеге формируются менее 5 соцветий, и количество цветков в соцветии обычно ниже, чем аналогичный показатель предыдущего возрастного состояния.

Постгенеративный период представлен синильными особями. Их очень мало. Они формируют только вегетативные побеги в крайне незначительном количестве (1-3). Новых генеративных побегов не образуется, в то время как побегов прошлого года можно наблюдать до 8.

\section{Выводы}

1. Для выделения возрастных периодов и состояний Onobrychis majorovii использовались качественные и количественные признаки морфометрии особей, соотношение процессов новообразования и отмирания.

2. Результаты проведенных исследований позволили выделить в жизненном цикле Onobrychis majorovii 4 возрастных периода и 9 возрастных состояний.

3. Наибольшей изученностью характеризуется генеративное возрастное состояние, которое представлено не только максимальными размерами особей, но и уравновешиванием процессов новообразования и отмирания.

4. Исследования требуют логического продолжения для корректировки диагностических признаков и уточнения продолжительности периодов и стадий жизненного цикла.

\section{Литература}

1. Алиева 3.М., Мартемьянова В.К., Юсуфов А.Г. Специфика морфогенеза изолированных структур редких растений Дагестана in vitro // Фундаментальные исследования. - 2014. - № 6. - С. 58-62.

2. Магомедалиева В.К., Алиева 3.М. Перспективы размножения редких и исчезающих видов растений in vitro // Вестник Дагестанского государственного университета. - Cер. 1. Естественные науки. 2012. - Вып. 6. - С. 167-171.

3. Магомедова М.А., Аджиева А.И. Состояние репродуктивного потенциала Colutea orientalis Mill. во Внутригорном Дагестане // Современные проблемы науки и образования. - 2015. - № 6 . 
4. Мамаева 3.К., Аджиева А.И. Эндемичные растения на территории плоскостного Дагестана // Вестник Дагестанского государственного университета. Сер.: Естественные науки. - 2004. - Вып. 4. - С. 87-86.

5. Аджиева А.И. Некоторые итоги изучения растительного покрова бархана Сарыкум (Дагестан) // Вестник Дагестанского государственного университета. Сер.: Естественные науки. - 2007. - Вып. 4 - С. 54-57.

6. Муртазалиев Р.А. Анализ эндемиков флоры Восточного Кавказа и особенности их распространения // Вестник ДНЦ РАН. - 2012. - № 47. - С. 81-85.

7. Литвинская С.А., Муртазалиев Р.А. Кавказский элемент во флоре Российского Кавказа: география, созология, экология: монография. - Краснодар, 2009. - 439 с.

8. Тайсумов М.А., Омархаджиева Ф.С. Анализ Флоры Чеченской Республики. Грозный, 2012. - 320 с.

9. Аджиева А.И. Сводный список видов флоры бархана Сарыкум // Вестник Дагестанского государственного университета. Сер.: Естественные науки. - 2008. - Вып. 1. - C. 52-58.

10. Майоров A.A. Эоловая пустыня у подножия Дагестана. - Махачкала: Дагестанский научно-исследовательский институт, 1928. - 116 с.

11. Аджиева А.И., Магомедова Н.А. Изучение редких видов массива Сарыкум // Вестник Академии наук Чеченской Республики. - 2011. - № 2 (15). - С. 28-31.

12. Шахбанова 3.3. Популяционное изучение Onobrychis majorovii Grossh на массиве Сарыкум // Природные и антропогенные изменения аридных экосистем и борьба с опустыниванием: материалы Международной научно-практической конференции, посвященной 20-летию журнала «Аридные экосистемы», 20-летию вступления в силу конвенции ООН по борьбе с опустыниванием, 40-летию Конференции ООН по борьбе с опустыниванием. - Махачкала: Институт геологии ДНЦ РАН, АЛЕФ, 2016. C. 219-222.

13. Бийболатова 3.А., Аджиева А.И. Онтогенетическая структура ценопопуляций эндемичного дагестанского вида Scabiosa gumbetica Boiss // Международный журнал прикладных и фундаментальных исследований. - 2014. - № 10. - С. 43-47.

14. Зубаирова Ш.М. Анатов Д.М. Изменчивость морфологических признаков в ценопопуляциях Hedysarum daghestanicum Rupr. ex Boiss // Известия Самарского НЦ PAH. - 2012. - T. 14, № 1 (7). - C. 1735-1737.

15. Магомедова Н.А., Аджиева А.И., Османова Х.О. Состояние ценопопуляции Jurinea ciscaucasica (Sosn.) Iljin. на массиве Сарыкум // Юг России: экология, развитие. - 2013. - № 2. - C. 103-111.

16. Брынза E.A. Морфоструктура особей и диагностический комплекс ключевых признаков онтогенетических состояний в ценопопуляциях Onobrychis vicifolia // Бюллетень ГНБС. - 2014. - Вып. 113. - С. 28-33.

17. Абачев К.Ю. Флора и растительность бархана Сарыкум и их охрана. - Махачкала, 1995. - 45 с.

Поступила в редакиџюю 16 июля 2017 г. 
UDC 581.527.4

DOI: $10.21779 / 2542-0321-2017-32-3-111-117$

\section{Primary diagnosis of Onobrychis majorovii Grossh age-related conditions}

\section{Z.Z. Shakhbanova}

Dagestan State University; Russia, 367001, Makhachkala, M. Gadzhiev st., 43a; shahbanova.zaryat@yandex.ru

A primary attempt was made to diagnose the age-related conditions of Onobrychis majorovii Grossh great life cycle on the sand massif Sarykum, located in the piedmont geomorphological part of Dagestan. Onobrychis majorovii - psammophilous, polycarpic perennial, heliophyte, is an endemic of the Eastern Caucasus. For the first time it was discovered and described by A.A. Mayorov on the territory of this sandstone nature monument in 1928. The plant grows in the reserve part of the massif, on the southern slope, closer to the base, it is exclusively decorative during the mass flowering in May. The data used to write the article are field collections of 2016, carried out in a gentle manner without excavating the plants taking into account the protected area of the survey. We used the morphometric (the venation, the shape and type of the leaf, the shoot growth characteristics, the weight, the color of the seminal rind and the seed form) and the quantitative (number of signs of the vegetative and generative spheres) features to study the morphology of individuals and the isolation of the ontogenetic period and the age-related state. The Onobrychis majorovii great life cycle is represented by 4 ontogenetic periods and 9 age-related states. The detailed description of each age condition and features of its allocation within the framework of the big life cycle Onobrychis majorovii are given in this article. We based on the data of the primary field research and some data of earlier studies of K.U. Abachev. Preliminary conclusions about the demographic structure of the studied cenopopulation have been made.

Keywords: Onobrychis majorovii, life cycle, age periods.

Received 16 July, 2017 